\title{
The plasmids of Acetobacter xylinum and their interaction with the host chromosome
}

\section{S. Valla, D.H. Coucheron, and J. Kjosbakken}

Laboratory of Biotechnology, The Norwegian Institute of Technology, The University of Trondheim, N-7034 Trondheim-NTH, Norway

Mol Gen Genet (1987) 208: 76-83

The correct Table 2 should read:

Table 2. Conjugative transfer of plasmids between A. xylinum strains

\begin{tabular}{llllll}
\hline Donor & \multicolumn{2}{l}{ Recipient } & & \multicolumn{2}{l}{ Transconjugant } \\
\cline { 2 - 3 } \cline { 5 - 6 } & $\mathrm{A}^{\mathrm{a}}$ & $\mathrm{B}^{\mathrm{b}}$ & & $\mathrm{A}^{\mathrm{a}}$ & $\mathrm{B}^{\mathrm{b}}$ \\
\hline class L (16.64) & class L & class H & & class L (16.64) & class L (n.d.) \\
class I (16) & class L & class H & & class I (16) & class H (44) \\
class I (49) & class L & class H & & class I (49) & class H (49) \\
\hline
\end{tabular}

nd., not determined

The numbers refer to the size of the A. xylinum plasmids with a Tn1 insertion. Plasmid patterns designated class $\mathrm{L}, \mathrm{I}$, and $\mathrm{H}$ are as described in this report

${ }^{a}$ Data from Valla et al. (1986)

${ }^{b}$ Data from this report

${ }^{c}$ Deduced from hybridization analysis. The plasmid band was invisible after EtBr staining of the gel 